Leda Maria Delmondes ${ }^{1}$

Mário Augusto Ferreira CruZ ${ }^{1}$

Matheus Kummer Hora Guimarães ${ }^{1}$

LUAN GaRCEZ Santana ${ }^{1}$

Valma Passos Chagas Gonçalves ${ }^{2}$

\title{
Esquistossomose endocervical: relato de caso
}

\author{
Endocervical schistosomiasis: case report
}

Relato de Caso

Palavras-chave

Schistosoma mansoni Esquistossomose mansoni Doenças do colo do útero Relatos de casos

Keywords

Schistosoma mansoni Schistosomiasis mansoni Uterine cervical diseases Case reports
Correspondência Leda Maria Delmondes Freitas Trindade Avenida Murilo Dantas, 300 - Farolândia CEP: 49032-490 Aracaju (SE), Brasil

Recebido $28 / 08 / 2013$

Aceito com modificacọōes $12 / 03 / 2014$

\section{Resumo}

A esquistossomose mansoni, endemia encontrada em diferentes áreas do território brasileiro, constitui um grave problema de saúde pública no Brasil e no mundo. Formas ectópicas da doença podem acometer o sistema reprodutor feminino, constituindo um tipo raro de infecção pelo S. mansoni. Paciente com 26 anos queixava-se de corrimento vaginal, dispareunia e dor à palpação do hipogástrio. No exame ginecológico foi observado pólipo endocervical, que foi biopsiado. O exame histológico evidenciou vários granulomas envolvendo ovos degenerados e viáveis de Schistosoma mansoni. Tratada com praziquantel, retornou assintomática após quatro semanas do tratamento. Corrimento vaginal e dispareunia podem ser causas secundárias de cervicite por Schistosoma mansoni. Pesquisa de ovos em esfregaço vaginal de rotina ou exame histológico devem fazer parte da avaliação ginecológica de pacientes de área endêmica, com o objetivo de rastrear forma ectópica da esquistossomose do trato genital feminino.

\section{Abstract}

Schistosomiasis mansoni is found in different endemic areas of Brazil. It is a serious public health problem in Brazil and worldwide. Ectopic forms of the disease may affect the female reproductive system, representing a rare type of Schistosoma mansoni infection. A 26-year-old patient complained of vaginal discharge, dyspareunia and pain on palpation of the hypogastrium. Gynecological examination revealed an endocervical polyp. A biopsy was performed. Under microscopy, several granulomas surrounding degenerate and viable eggs of Schistosoma mansoni were seen. Treated with praziquantel, she was asymptomatic after four weeks of treatment. Vaginal discharge and dyspareunia may be secondary causes of cervicitis caused by Schistosoma mansoni. The search for eggs in routine vaginal smear or histological examination should be part of the gynecologic evaluation of patients from endemic areas, with the purpose of tracking ectopic schistosomiasis of the female genital tract.

\section{Departamento de Medicina da Universidade Tiradentes - Unit - Aracaju (SE), Brasil.}

'Universidade Tiradentes - Unit - Aracaju (SE), Brasil.

2Unidade Básica de Saúde Madre Tereza de Calcutá - Aracaju (SE), Brasil.

${ }^{3}$ SOLIM Laboratório de Patologia - Aracaju (SE), Brasil.

Conflito de interesses: não há. 


\section{Introdução}

Esquistossomoses são enfermidades parasitárias produzidas por trematódeos do gênero Schistosoma, sendo S. Haematobium, S. mansoni, S. intercalatum, S. Japonicum e $S$. mekongi os principais agentes etiológicos que acometem o homem. Mais de 200 milhões de pessoas estão infectadas na África, Ásia e América do Sul, e perto de 800 milhões estão em risco de infeção ${ }^{1}$. A esquistossomose é prevalente em áreas tropicais e subtropicais, especialmente em locais sem acesso ao saneamento adequado. No Brasil, a esquistossomose mansônica foi identificada em 1908, sendo a espécie $S$. mansoni a mais comum e o único schistossoma com transmissão estabelecida no Brasil. Estima-se que, no Brasil, 25 milhões de pessoas vivam em áreas endêmicas ${ }^{2}$.

A transmissão do S. mansoni ocorre em 19 Estados brasileiros, é considerada endêmica em 9 deles e contribui para o ciclo da pobreza ${ }^{2}$. No Estado de Sergipe são detectados altos índices de positividade dessa infecção ${ }^{3}$. A distribuição geográfica da endemia nos Estados da Bahia, Sergipe e Alagoas atinge 68\% do território, e em Pernambuco atinge em torno de 39\%. Entre 2005 e 2010, o Brasil realizou inquérito coprológico que revelou que, das 10.783.144 pessoas examinadas, 647.861 eram portadoras da infecção pelo S. mansoni $i^{4-6}$.

A infecção por $S$. mansoni inclui uma variedade de manifestações clínicas e tem apresentação polimórfica, sendo a forma hepatointestinal a mais frequente. A resposta imune aos ovos de Schistosoma spp aprisionado em tecidos humanos provoca doença hepatoesplênica e fibrose hepática ( $S$. mansoni e $S$. japonicum), além de resposta inflamatória no trato geniturinário (S. haematobium). São consideradas formas ectópicas quando o elemento parasitário — ovos ou vermes adultos — se localiza fora do sistema porto-cava. Órgãos como pulmões, pâncreas, rins, linfonodos, tireoide, coração, assim como o sistema nervoso central, o sistema urinário e o trato genital feminino (colo uterino, corpo uterino, vagina, vulva, clitóris, uretra, ovário e tuba uterina) podem conter ovos do helminto ${ }^{7-12}$.

A esquistossomose do trato genital feminino é uma forma rara de infecção pelo $S$. mansoni, sendo que o $S$. haematobium acomete o trato genital feminino em torno de 33 a $73 \%$ dessas situações ${ }^{13}$.

A contaminação do homem se inicia quando as cercárias infectadas, que foram liberadas pelos caramujos do gênero Biomphalaria, penetram na pele no momento da exposição à água contaminada. No tecido subcutâneo, as cercárias se transformam em esquistossômulos e, em dois a quatro dias, migram para os vasos venosos ou linfáticos, alcançando os pulmões, e por último o parênquima hepático. Quando os vermes maturam sexualmente, migram para locais específicos, como o plexo venoso mesentérico e as veias vesicais, ondem podem viver por cinco a dez anos. Depois que a cópula acontece, as fêmeas grávidas seguem contra o fluxo da corrente sanguínea, depositando seus ovos dentro do espaço intravascular dos pequenos vasos tributários ${ }^{7}$. A patogênese da esquistossomose mansoni depende da interação parasita-hospedeiro e está relacionada com os locais de oviposição, número de ovos depositados e reação do hospedeiro aos seus antígenos $^{14}$. A resposta imunitária do hospedeiro facilita a replicação do parasita. O granuloma se constitui em lesão típica e envolve os ovos depositados pelos parasitas. Essa resposta inflamatória granulomatosa compõe uma reação tipo tardia mediada por células T CD4 que podem desencadear uma resposta Th1 ou Th2, que estimula a produção de anticorpos (IgE) e maior produção de eosinófilos ${ }^{15}$.

O objetivo deste artigo, além de apresentar um caso de esquistossomose mansoni endocervical, é chamar a atenção para a importância de se investigar a esquistossomose mansoni em trato genital de mulheres que residem em áreas endêmicas.

\section{Descrição do caso}

Estudo aprovado pelo Comitê de Ética e Pesquisa em Seres Humanos da Universidade Tiradentes, Aracaju, Sergipe, sob número 350912. A paciente assinou o Termo de Consentimento Livre Esclarecido, de acordo com a Resolução CNS 196/96. Os dados foram obtidos durante consulta, exames ginecológico, bioquímico, coprológico e de imagem (ultrassonografia abdominal total e transvaginal), além de colposcopia e colpocitologia.

A paciente estudada era uma mulher de 26 anos, casa$\mathrm{da}$, procedente do interior de Sergipe, atendida na Unidade de Saúde da Família Madre Tereza de Calcutá em Aracaju, Sergipe, no dia 15 de fevereiro de 2012. Referia queixa de dor abdominal em hipogástrio, corrimento vaginal de aspecto levemente amarelado, dispareunia e dismenorreia, que piorava com a menstruação; ciclo menstrual regular; aborto espontâneo há 10 anos, sendo submetida a uma curetagem; exame de Papanicolau realizado um mês antes da consulta; antecedentes familiares sem alterações; bom estado geral. Referiu dor à palpação superficial e profunda em hipogástrio. Ausência de visceromegalias. Colposcopia e colpocitologia: colo uterino de tamanho médio, apresentando uma lesão friável no orifício externo, com aspecto de couve-flor. Presença de um pólipo endocervical e secreção vaginal amarelada sem odor; zona de transformação e orifícios glandulares normais; vasos típicos regulares. Teste de Schiller negativo. Enviadas amostras da lesão e do pólipo para estudo histopatológico.

A paciente retornou em 24 de abril de 2012 com ultrassonografia do abdome total e transvaginal revelando líquido em pelve e útero bicorno. O laudo histopatológico foi: análise macroscópica e microscópica de quatro fragmentos de tecido polipoide medindo, o maior deles, $0,6 \times 0,3 \times$ $0,2 \mathrm{~cm}$; fragmentos irregulares e uma de suas faces coberta por epitélio de cor acastanhada opaca e consistência elástica. 
Microscopicamente: cortes histológicos exibem pólipo endocervical (Figura 1) e esquistossomose em mucosa endocervical, caracterizada por múltiplos granulomas envolvendo ovos viáveis e degenerados de S. mansoni no córion (Figura 2). Presença de reação inflamatória crônica inespecífica rica em eosinófilo no tecido circundante (Figura 3).

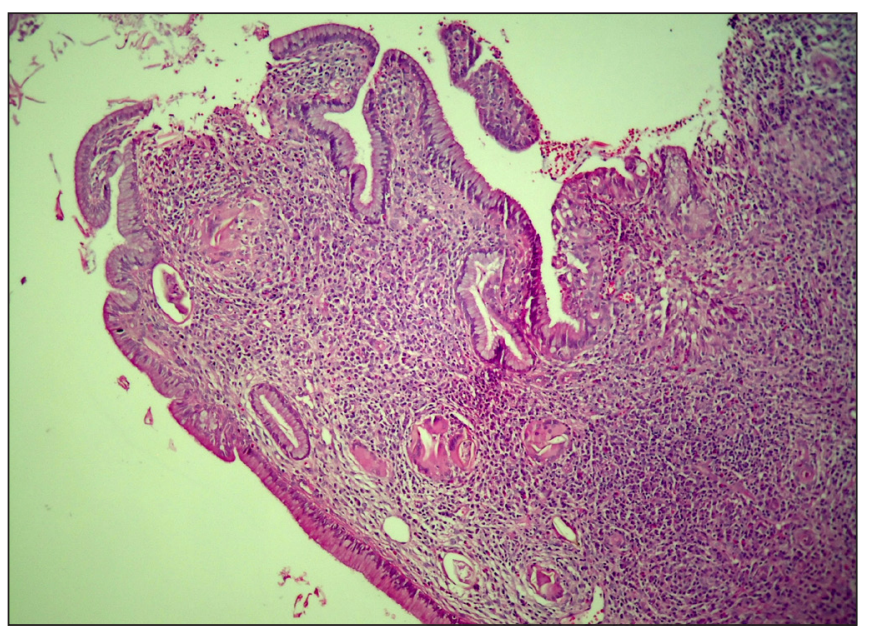

Figura 1. Formação polipoide de mucosa endocervical, revestida por epitélio colunar simples muco secretor, sem atipias, com reação inflamatória crônica granulomatosa no córion

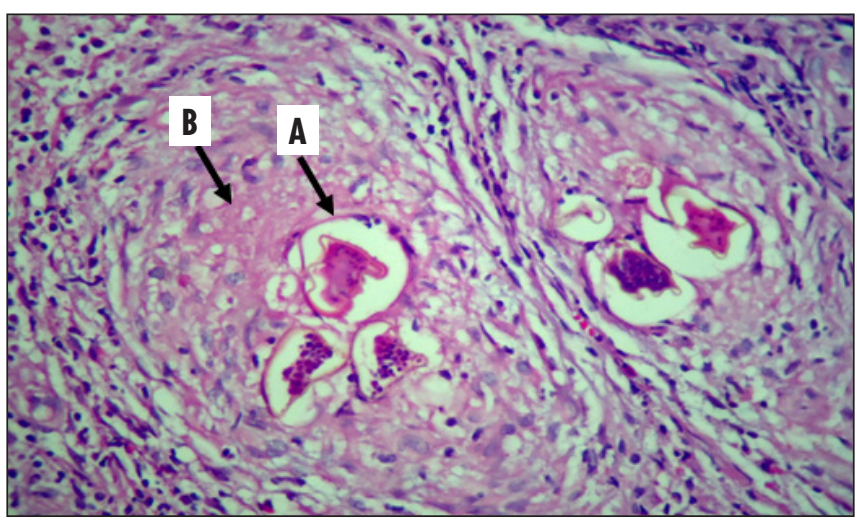

Figura 2. Ovos de $S$. Mansoni (A) circundados por células epitelioides (B) formando o granuloma no córion endocervical

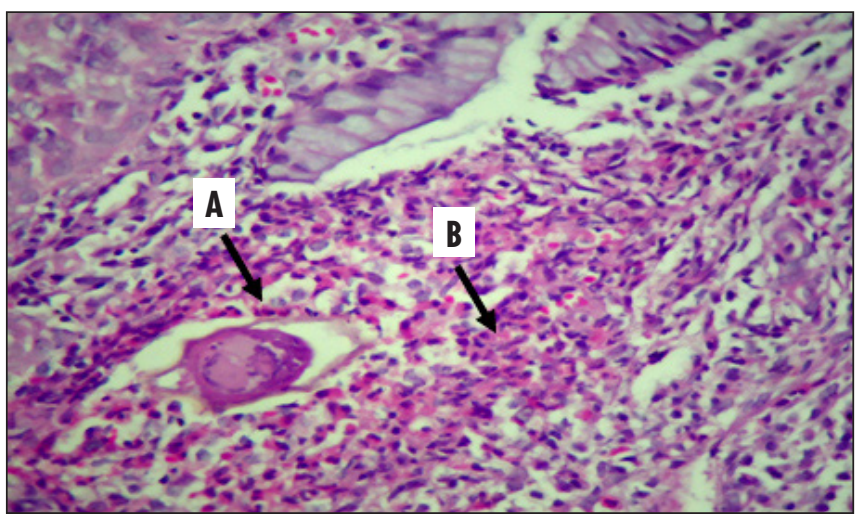

Figura 3. Granuloma envolvendo ovo viável de S. Mansoni (A) adjacente ao epitélio endocervical, formado por células epitelioides e abundantes eosinófilos (B)
Foi utilizado Praziquantel $(50 \mathrm{mg} / \mathrm{kg})$ em dose única. Não houve relato de efeitos colaterais.

Após quatro semanas, a paciente retornou ao ambulatório com regressão dos sintomas e das lesões endocervicais. Em 28 de junho de 2012, o exame coprológico revelou resultado negativo para parasitoses. Reavaliada em 15 de agosto de 2012, não apresentava queixas.

Ao exame clínico apresentava vulvoscopia dentro dos limites da normalidade. Exame colposcópico evidenciou secreção vaginal branca leitosa, sem odor. Ausência de lesões no colo do útero. Teste de Schiller negativo. O exame ginecológico não mostrava anormalidades, exame coprológico (fresco e três amostras) negativos para parasitoses e ultrassonografia transvaginal sem novos achados.

\section{Discussão}

A suspeita inicial de carcinoma para a lesão encontrada na paciente não foi confirmada pela histopatologia; nos exames coprológicos não foi detectado $S$. mansoni. Entretanto, um resultado negativo não afasta a possibilidade de infestação, visto que a pesquisa pode ser ocasionalmente negativa em estágios precoces da infecção ou em infecções crônicas. Em 1.250 amostras de biópsia de colo de portadoras de esquistossomose sistêmica, apenas 4 casos $(0,3 \%)$ apresentaram lesão de colo uterino (carcinoma in situ, carcinoma de células escamosas invasivo do colo uterino, lesão cervical benigna). Na lesão cervical benigna foram detectados ovos do parasita, porém, estudos posteriores afirmaram que o carcinoma estaria associado à coinfecção pelo papiloma vírus humano (HPV) e não à esquistossomose $\mathrm{e}^{16,17}$.

A esquistossomose endocervical é um fator de risco para infecções por doenças sexualmente transmissíveis, especialmente pelo vírus da imunodeficiência humana (HIV) e pelo HPV. Isso ocorre devido a uma modificação da história natural e à resposta imunológica a tais infecções ${ }^{17,18}$.

É pouco conhecido o mecanismo pelo qual os ovos de S. mansoni vão para o trato genital feminino. Entretanto, vários estudos apontam que, nos casos de $S$. haematobium, muitos ovos do esquistossomo não conseguem sair do corpo e chegam a embolizar dentro dos leitos capilares de órgãos pélvicos, especialmente nos tecidos da bexiga, ureteres e os órgãos genitais femininos, onde induzem a formação de granulomas e, finalmente, pequenos nódulos ${ }^{19,20}$.

A esquistossomose endocervical está associada a uma grande variedade de sintomas clínicos. O quadro clínico se apresenta com dor em hipogástrio, dispareunia e dismenorreia, hemorragia (sangramento pós-coito e sangramento intermenstrual) ou leucorreia. A resposta imune do hospedeiro contra antígenos do parasita desempenha um papel crítico e sinaliza a gravidade da inflamação dos tecidos e das doenças associadas. 
Achados macroscópicos e histopatológicos nas amostras da paciente foram similares aos da literatura ${ }^{15}$, tais como aspecto de "couve-flor", hipertrofia nodular, ulcerativa e lesões nodulares. Microscopicamente, observou-se uma reação inflamatória intensa (células plasmáticas, linfócitos, eosinófilos e macrófagos) em torno dos ovos viáveis e uma reação inflamatória de tecido conjuntivo com infiltrado celular mínimo ao entorno dos ovos não viáveis.

Helling-Giese et al. ${ }^{21}$ identificaram esquistossomose urinária e genital em trinta e três mulheres em Malawi, infectadas por S. haematobium. Foram avaliadas através de exame parasitológico e ginecológico, e submetidas à colposcopia, com biópsia, para avaliação histopatológica e imunohistoquímica. Foram observadas respostas inflamatórias com algumas características específicas, semelhantes às encontradas na paciente em estudo. As seções histopatológicas das lesões demonstraram pequena reação celular em torno de ovos do $S$. haematobium em vários estágios de desinteg ração, além de reação imunológica acentuada, caracterizada por um infiltrado celular intenso em fragmento de lesão polipoide ${ }^{21,22}$.

O diagnóstico diferencial da esquistossomose genital feminina deve ser considerado para as pacientes que têm uma história de residência ou de viajar para áreas endêmicas.

Oxamniquine e praziquantel são fármacos utilizados no tratamento da esquistossomose. Contudo, ambos apresentam limitações, como baixa eficácia no tratamento da esquistossomose mansoni aguda, baixa atividade sobre o $S$. mansoni na forma imatura e falha em tratamentos, devido à ocorrência de resistência ou tolerância a esses fármacos ${ }^{23}$. A vacina contra a esquistossomose faz parte de recentes avanços no campo da genômica ${ }^{23-25}$. Até 2010, o Instituto Butantã, no Brasil, desenvolvia pesquisa no Projeto Temático Genoma funcional do Schistosoma mansoni aplicado ao desenvolvimento de vacinas ${ }^{26}$.

Apesar da descoberta de vários antígenos potencialmente promissores a partir de $S$. mansoni, $S$. japonicum e $S$. haematobium, apenas uma vacina ( $S$. haematobium) foi submetida a ensaios clínicos ${ }^{26}$. A prevenção e o controle da esquistossomose são baseados no tratamento em larga escala de grupos populacionais em situação de risco. O objetivo é reduzir a doença utilizando tratamento periódico para curar sintomas leves e evitar que pessoas infectadas desenvolvam doença crônica grave.

Corrimento vaginal e dispareunia podem ser causas secundárias de cervicite por $S$. mansoni. Pesquisa de ovos em esfregaços vaginais de rotina e exame histológico de amostras de biópsias devem fazer parte da avaliação ginecológica de pacientes de área endêmica, com o objetivo de rastrear a forma ectópica da esquistossomose no trato genital feminino. Considerando que os índices de prevalência em municípios dos Estados do Nordeste ainda sejam elevados, acredita-se que a subnotificação e a falta de uma investigação mais dirigida sejam responsáveis pela ausência de diagnósticos de formas ectópicas dessa enfermidade parasitária. Este estudo sinaliza a importância epidemiológica no diagnóstico dessa infecção, no sentido de diagnosticar novos casos de apresentação ectópica de esquistossomose mansoni no trato genital feminino.

\section{Agradecimentos}

Ao SOLIM Laboratório de Patologia.

\section{Referências}

1. World Health Organization (WHO). Sustaining the drive to overcome the global impact of neglected tropical diseases: second $\mathrm{WHO}$ report on neglected tropical diseases. Geneva: $\mathrm{WHO} ; 2013$.

2. Nascimento GL, Oliveira MR. Severe forms of schistosomiasis mansoni: epidemiologic and economic impact in Brazil, 2010. Trans R Soc Trop Med Hyg. 2014; 108(1):29-36.

3. Rollemberg CV, Santos CM, Silva ML, Souza AM, Silva AM, Almeida $\mathrm{JA}$, et al. Aspectos epidemiológicos e distribuição geográfica da esquistossomose e geo-helmintos, no Estado de Sergipe, de acordo com dados do programa de Controle da Esquistossomose. Rev Soc Bras Med Trop. 2012:44(1):91-6.

4. Leal Neto OB, Galvão TY, Esteves FA, Gomes AM, Gomes EC, Araújo KC, et al. Spatial analysis of schistosomiasis human cases the horticultural community of Zona da Mata of Pernambuco state, Brazil. Rev Bras Epidemiol. 2012;15(4):771-80.

5. Leal Neto OB, Gomes EC, Oliveira Junior FJ, Andrade R, Reis $D L$, Souza-Santos R, et al. Biological and environmental factors associated with risk of schistosomiasis mansoni transmission in Porto de Galinhas, Pernambuco State, Brazil. Cad Saúde Pública. 2013;29(2):357-67.

6. Palmeira DC, Carvalho AG, Rodrigues K, Couto JL. Prevalência da infecção pelo Schistosoma mansoni em dois municípios do Estado de Alagoas. Rev Soc Bras Med Trop. 2010;43(3):313-7.

7. Gray DJ, Ross AG, Li YS, McManus DP. Diagnosis and management of schistosomiasis. BM. $2011 ; 342:$ d2651.

8. Coyle CM. Schistosomiasis of the nervous system. Handb Clin Neurol. 2013;114:271-81. 
9. Badiale GB, Brandão DF, Ribeiro-Silva A. Esquistossomose endocervical. Rev Soc Bras Med Trop. 2005;38(4):351-2.

10. Adeniran A, Dimashkieh $H$, Nikiforov Y. Schistosomiasis of the cervix. Arch Pathol Lab Med. 2003;127(12):1637-8.

11. Chen W, Flynn EA, Shreefter M, Blagg NA. Schistosomiasis: an unusual finding of the cervix. Obstet Gynecol. 2012;119/2 Pt 2):472-5.

12. Poggensee $G$, Feldmeier H. Female genital schistosomiasis: facts and hypotheses. Acta Trop. 2001;79(3):193-210.

13. Coelho LH, Carvalho G, Carvalho JM. Carcinoma in situ and invasive squamous cell carcinoma associated with schistosomiasis of the uterine cervix a report of three cases. Acta Cytol. $1979 ; 23(1): 45-8$

14. Souza FP, Vitorino RR, Costa AP, Faria Júnior FC, Santana LA, Gomes AP. Esquistossomose mansônica: aspectos gerais, imunologia, patogênese e história natural. Rev Bras Clín Méd. $2011 ; 9(4): 300-7$

15. Abath FG, Morais CN, Montenegro CE, Wynn TA, Montenegro SM. Immunopathogenic mechanisms in schistosomiasis: what can be learnt from human studies? Trends Parasitol. 2006;22(2):85-91.

16. Mosunjac MB, Tadros T, Beach R, Majmudar B. Cervical schistosomiasis, human papilloma virus (HPV), and human immunodeficiency virus (HIV): a dangerous coexistence or coincidence? Gynecol Oncol. 2003;90(1):211-4.

17. Yirenya-Tawiah DR, Amoah CM, Apea-Kubi KA, Dade M, Lomo $G$, Mensah $D$, et al. Female genital schistosomiasis, genital tract infections and HIV co-infection in the Volta Basin of Ghana. Int J Trop Dis Health. 2013;3(2):94-103.

18. Kjetland EF, Leutscher PD, Ndhlovu PD. A review of female genital schistosomiasis. Trends Parasitol. 2012;28(2):58-65.

19. van Bogaert $L$. Biopsy-diagnosed female genital schistosomiasis in rural Limpopo, South Africa. Int J Gynaecol Obstet. $2011 ; 115(1): 75-6$

20. Eladl AE, Shebl AM, ElKashef WF, Zalata KR. Bilharzial endocervical polyp. Indian J Pathol Microbiol 2012;55(3):377-8.

21. Helling-Giese G, Sjaastad A, Poggensee G, Kjetlandc FE, Richterd J, Chitsuloe $L$ et al. Female genital schistosomiasis (FGS): relationship between gynecological and histopathological finding. Acta Tropica. 1996;62(4):257-267.

22. Eladl AE, Shebl AM, Elkashef WF, Zalata KR. Bilharzial endocervical polyp. Indian J Pathol Microbiol. 2012;55(3):377-8.

23. Silva KER, Silva RMF, Costa SPM, Rolim LA, Lima MCA, RolimNeto PJ. Alternativas terapêuticas no combate à esquistossomose mansônica. Rev Ciênc Farm Básica Apl. 2012;33(1):9-16.

24. Rofatto HK, Leite LC, Tararam CA, Kanno Al, Montoya BO, Farias LP. Antígenos vacinais contra esquistossomose mansônica: passado e presente. Rev Biol. 2011 ; 6b:54-9.

25. Brindley PJ, Hotez PJ. Break out: urogenital schistosomiasis and Schistosoma haematobium infection in the post-genomic era. PLoS Negl Trop Dis. 2013;7(3):e1961.

26. Mc Manus DP, Loukas A. Currente status of vaccines for schistosomiases. Clin Microbiol Rev. 2008;21(1):225-42. 